\title{
STRESS IN ALEX MICHAELIDAS' NOVEL THE SILENT PATIENT
}

\author{
Mai Sarah, Asnani \\ Faculty of Literature, Universitas Islam Sumatera Utara \\ Medan, Indonesia \\ e-mail: zainalmaysarah@gmail.com
}

Received: 2021-10-01

Accepted: 2021-11-09

\begin{abstract}
The study focuses on the stress experienced by the protagonist, Alicia Berenson. The main purpose of this study is to determine the types and the impacts of stress experienced by the protagonist by the name of Alicia Berenson, based on the theory of stress proposed by Priyoto (2014). In analyzing The Silent Patient, the researchers use qualitative research method to process and arranges the data. The data collected are divided into two categories i.e. primary data and secondary data. The primary data is the novel The Silent Patient (2019), and the researchers find fifteen data to be included in the analysis. The secondary data are books and other sources related to the analysis such as books or journals of stress issues, literary theory, the author's biography, internet and other relevant information to the analysis of this research paper. The data are collected through library research and searched based on the explanation from types and the impact of Stress proposed by Priyoto. The results of the study show the following conclusion. First, Alicia suffers from chronic stress which can be shown through impaired social relationships and nervousness. Second, the behavioral impact is shown through changes in the behavior system to be silent, aggressive behavior and self-injured.
\end{abstract}

Keywords: Stress, Chronic Stress, behavioral impact, aggressive behavior

\section{Introduction}

The Silent Patient is a novel written by British-Cypriot author, Alex Michaelides. The Silent Patient is his debut novel and published by Celadon Books, a division of Macmillan Publishers, on 5 February 2019. The Silent Patient is a psychological thriller novel set in a psychiatric treatment facility, Grove. This story is narrated by a British psychotherapist, Theo Faber, dealing with a patient who becomes mute after killing her husband. The theme of this novel is developed from the protagonist, Alicia Berenson, who suffers from mental illness and the plot describes the suffering she experiences after the death of her husband, Gabriel. In this case, the problem to be studied focuses on the stress that occurs in the character, namely Alicia Berenson.

Stress is a depressed condition experienced by an individual due to demands or inconsistencies and the reaction depends on how the individual copes with it. According to Palupi (2004) stress is defined as the inability to cope with the threats faced by a human being mentally, physically, emotionally, and spiritually, which at one time can 
affect his physical condition. Sarafino, et.al (2015) define that stress as a condition caused by interactions between individuals and the environment, causing a perception of the distance between demands that come from situations that originate in a person's biological, psychological and social systems. According to Spielberger (1979), stress is external demands on a person, for example an object in the environment or a stimulus that is objectively dangerous. Stress may also be interpreted as pressure, tension, unpleasant disturbances that come from outside a person.

There are several reasons why researchers are interested in researching the topic of stress in this novel. The first is because this topic is the main theme of this novel. In addition, many moral lessons can be learned from this research. Readers will understand the types of stress, the effects of stress and of course how to overcome and avoid stress.

Every person on this earth must ever encounter stress in their life and various factors can be its trigger. Stress is an unavoidable part and can affect every level of people regardless of age, gender, social status, occupation, religion and others. Stress can also be found anywhere, at school, at work, in friendships, in love relationships, and so on. Stress is a problem that can be faced by everyone. Every person on this earth must have stress in their life and various factors can be the stressor.

With the above points in mind, it is explained that Alicia suffers from stress that can endanger her life. Various characteristics of the types and impacts of Alicia's stress can be found in this novel. Thus, it seems that Alicia Berenson's stress problem is a very interesting topic to be researched. By reading this novel, the writer would like to analyze the theme which exists in this novel, namely stress and the researchers would like to analyze in detail.

\section{Literature Review}

Protagonist is the chief character in a plot, on whom our interest centre or alternatively the hero or heroine. (Abrams and Geoffrey, 1999). According to Fowler (2001), the protagonist is the main character in the story, novel, drama, of other literary work, the character that the reader or audiences emphasizes with.

Based on some understandings of protagonist above, a protagonist can be defined as the leading character or one of the major characters in a drama, movie, novel, or other fictional text. Basically, protagonist is a reflection of the story or theme raised by the author. Furthermore, the main character is often used as the conveyor of the contents of the story or the message that is implied. This shows that the protagonist is very influential in the course of a story, both in novels and in other literary works.

According to Jordan (1997), stress is any change in yourself, both internally and externally, which causes reactions from individuals. There are also those who mention stress as the body's reaction to situations that press, or threaten someone. Chaplin (2001) states that stress is a state of depression, both physically and psychology, but in general it can be divided into two i.e. facing it or running away from the situation. If a person faces it, then there are two possibilities, namely if the person is successful the stress will pass and end. But if the stress itself is too heavy, it continues, or the person chooses to face it but fails, then there can be physical problems, psychological changes (depression), changes in attitude that can increase anxiety, then increase to stress.

According to Priyoto's theory (2014), types of stress are divided into three: Acute Stress, Episodic Acute Stress and Chronic Stress. These types will be explained further below. 
1. Acute stress is a stressor that everyone faces on a regular basis, such as lots of sleep, traffic jams, and criticism from superiors. Acute stress situations last only a few minutes or hours. The characteristics of acute stress are increased enthusiasm, sharp eyesight, increased energy but decreased energy reserves, increased ability to complete lessons, often feeling tired without cause, sometimes there are system disorders such as digestion, brain, and feeling not relaxed. Acute stress is useful because it can spur a person to think and try to be more resilient in facing life's challenges.

2. Episodic Acute Stress lasts longer than acute stress. Unresolved situations with colleagues, sick children, or prolonged absence from family members can be the causes of Episodic Acute Stress. The characteristics of Episodic Acute Stress are abdominal pain, mules, relaxed muscles, feeling tense, sleep disturbance, and the body feels light.

3. Chronic stress is a situation that has been felt by a person for a long time, which can last from several weeks to several months, such as continuous marital disputes, longlasting financial difficulties due to no improvement, separation from family, changing places of residence, having chronic illnesses and including physical, psychological-social changes in the elderly. The characteristics of chronic stress are nervousness, anxiety, panic, frustration, difficulty in doing activities, impaired social relationships, difficulty sleeping, negativity, decreased concentration, fear of unclear, increased fatigue, inability to do simple work, increased system disturbances, increased fear.

According to Priyoto's theory (2014), the impacts of stress are divided into three categories, namely:

\section{Physical Impact}

The physical impact of stress includes three characteristics. First, disorders of hyperactive organs in one particular system. It is characterized by muscle myopathy (certain muscles tighten / weaken), increased blood pressure (damage to the heart and arteries), and digestive system (ulcers, diarrhea). Second, reproductive system disorders. It is characterized by amenorrhea (suspension of menstruation), ovulation failure in women, impotence in men, less semen production in men, and loss of sex drive. Third, other disorders, such as dizziness (migraine), muscle tension, boredom, etc.

\section{Psychological Impact}

The psychological impact of stress includes two characteristics. First, emotional overload (exhaustion), saturation, and appreciation are the first signs, and have a central role in the occurrence of burn-out. Second, decreased personal achievement, resulting in decreased sense of competence and a sense of success.

\section{Behavioral Impact}

The behavioral impact of stress includes three characteristics, i.e. silence, aggressiveness, and self-injury. Silence is caused by disorders of organs such as the throat, vocal cords, lungs, mouth, tongue, and so on. Someone who becomes silence that is not acquired from birth can be said as a change in behavior. Behavior is the result of all kinds of experiences and human interactions with their environment which are manifested in the form of knowledge, attitudes and actions. Behavior is an individual's response/reaction to stimuli that come from outside or from within himself. Krahe 
(2005) argues that aggressive is any form of behavior that is intended to hurt or injure other living beings who are driven to avoid that behavior. According to Kartono (2000), aggressiveness is anger that overflows and people attack violently in an unnatural way. The aggressive behavior is behavior that aims to injure or hurt someone or something, both verbally and nonverbally, which causes hostility. Klonsky (2011), states that selfinjury is a form of behavior carried out by individuals to emotional pain, this behavior is done very deliberately but the individual has no intention of committing suicide. Selfinjury is also a form of self-defense mechanism that a person uses to deal with emotional pain, self-emptiness, loneliness, loss, and satisfying the desire to punish oneself by causing injuries to the body. According to Mazelis (2008) self-injury is intentionally injuring one's own body as a way of dealing with emotional problems and stress. People hurt themselves not to create physical pain, but to soothe deep emotional pain,

\section{Research Method}

"Protagonist Stress in Alex Michaelidas' Novel The Silent Patient" discusses stress experienced by the protagonist, Alicia Berenson. This research is analyzed based on Konsep Manajemen Stress proposed by Priyoto (2014). In conducting this study, the qualitative research method was used to process and to arrange the data. According to Walliman (2010: 71), qualitative research explores people's judgment, feeling of comfort, emotions ideas, beliefs etc, and it can be described in words. Therefore, the researchers present the analysis and finding from the discussion form.

The researchers conducted this study through some steps: quoting and marking some phrases and sentences related to protagonist's stress in the novel; finding and taking another data such as books or journal of stress issues, literary theory, the author's biography, and other relevant information to the analysis of this research; and classifying and reviewing data based on problem formulation criteria to find answers to problems.

\section{Discussion}

Stress is a common problem that occurs in human life. Now, the demands and pressures of life are getting heavier. This can cause a person to become stressed and various factors and reasons can be the stressor. For instance, tiring work, criticism from others, or unwanted events. In this chapter, the analysis discussion focuses on the stress experienced by the protagonist, Alicia Berenson.

\subsection{Chronic Stress}

Chronic stress is a situation that is felt by a person for a long time, which is from several weeks to several months (Priyoto, 2014). Based on the analysis of researchers in the novel, Alicia Berenson suffers from one type of stress, namely chronic stress. This can be shown in two characteristics, namely impaired social relationship and nervousness.

\subsubsection{Impaired Social Relationship}

Impaired social relationship is one of the characteristics of chronic stress. This can affect a person's behavior, causing problems in personal or interpersonal relationships. Stressful behavior can make a person be positive or negative. Negative stress behavior (distress) can cause an individual to do things that are not normal to his 
environment. This abnormality causes the relationship between the individual and his environment to be problematic and ultimately rejection by environment occurs. Alicia has impaired social relationship and it can be seen in the following quotation.

She refused to visit me in my office, so I went to see her in her room.

During the sessions, she simply sat on her bed and stared out of the window. She refused to speak, of course. She refused to even look at me." He threw up his hands, exasperated. "I decided the whole thing was a waste of time.” (Michaelidas, 2019: 38).

The quotation above explains that Alicia Berenson refuses to visit her psychotherapist, Theo Faber. In the therapy session, Alicia does not even talk to Theo. She just sits on his bed and looks out the window. She does not notice Theo's presence. This explains that Alicia has an impaired social relationship. One of the characteristics of a good social relationship with the environment is to respond and appreciate when someone tries to talk to us. These traits cannot be shown by Alicia in her behavior.

\subsubsection{Nervousness}

Nervousness is one of the hallmarks of chronic illness. Nervousness is doing or saying in an uneasy state: stuttering, very hasty, and confused. It can also be defined as one of the body's natural responses to stress. It is a feeling of fear or worry about what's to come. The most common responses to nervousness are tension, fear, worry such as heart palpitations, shaking hands or feet, hesitation to act, dry mouth and cold sweat. Alicia experiences symptoms of anxiety as a result of the stress she suffers and these symptoms are shown in several paragraphs in the novel The Silent Patient. This can be seen in the quotation below.

Alicia hesitated. She glanced at him, then made a decision. She walked into the room, slightly unsteadily. She sat on a chair, silent as a cat (Michaelidas, 2019: 41).

Nervousness usually occurs when a person cannot control herself. Through the quotation above, it can be explained that Alicia has a nervous breakdown. The response to the nervousness experienced by Alicia from the quotation above is her hesitation to act. Just as she was about to enter to the room, Alicia walks unsteadily and looks hesitant. In the room, Alicia just sits quietly on the chair, scares like a cat.

\subsection{Behavioral Impact}

Behavioral impact is one categories of impact of stress. In this session, the writer only focuses on stress that has an impact on the behavior of the protagonist, Alicia Berenson. Through the author's research, there are several impacts that can be seen from Alicia's behavior, namely behavioral system change (silence), aggressive behavior, and self-injury.

\subsubsection{Silence}

Behavioral system change is one of the characteristics of heavy stress (Priyoto, 2014). Silence is one example that can be shown from the changes in the behavioral system experienced by Alicia. Alicia is silent because of her mental unpreparedness for the tragedy of her husband's death. This change in behavior is usually caused by shock or mental unpreparedness for an event. This can be seen in the quotation below. 
The following day, she lay in bed in a private room in the hospital. The police questioned her in the presence of her lawyer. Alicia remained silent throughout the interview. Her lips were pale, bloodless; they fluttered occasionally but formed no words, made no sounds. She answered no questions (Michaelidas, 2019: 15).

The quotation above shows Alicia's behavior changing to being silent when the police questioned her. Alicia does not answer a single question. The quotation also explains that Alicia wants to say something but her lips tremble and ends up not making any sound. Alicia remains silent and never says anything. This explains that Alicia has a behavior change that was silence.

\subsubsection{Aggressive}

Aggressive behavior is one of the effects of changing the behavior of someone who is experiencing stress. Stress that is followed by anger produces negative behavior that causes aggressive behavior. Aggressiveness is anger that overflows and people attack violently in an unnatural way. Anger is a response to anxiety that is perceived as a threat. These aggressive behaviors are explained further through the following quotation.

Only one incident stood out. It took place in the canteen, a few weeks after Alicia's admission. Elif accused Alicia of taking her seat. What exactly had happened was unclear, but the confrontation escalated rapidly. Apparently Alicia became violent-she smashed a plate and tried to slash Elif's throat with the jagged edge. Alicia had to be restrained, sedated, and placed in isolation (Michaelidas, 2019: 45).

Through the previous quotation, stress followed by anger causes aggressive behavior. Alicia's aggressive behavior is clearly illustrated in the quotation above. Alicia's aggressive behavior occurs in the grove canteen. Alicia is angry that Elif accuses her of taking her seat, which then a confrontation quickly ensues. Alicia acts brutally by breaking her plate and tries to harm Elif by cutting her throat with a jagged edge. As an impact of her aggressive behavior, Alicia has to be arrested, sedated and placed in isolation. Alice's behavior is a manifestation of the threat directed at her and one way to fight this threat is to act aggressively.

\subsubsection{Self-Injury}

Self-harm is one of the behavioral impacts. This can be defined as the inability to overcome the threats faced by the mental, physical, emotional, and spiritual of humans, which at some point can affect human behavior. Excessive mental stress can make individuals do negative things, such as hurting themselves. Stress due to trauma can also be a trigger for self-harm. In this novel, Alicia attempts suicide several times after the death of her husband, Gabriel. This can be seen from the following quotation.

And then something glinted in the torchlight - a knife was on the floor by Alicia's feet. Another beam of light revealed the blood spattered on Alicia's white dress. An officer grabbed her arms and held them up to the light. There were deep cuts across the veins in her wrists-fresh cuts, bleeding hard (Michaelidas, 2019: 14). 
The quotation above shows that Alicia hurts herself in an attempted suicide. This incident happens at Alicia's house. Police find Alicia with a slashed wrist and a knife lying next to her. Blood is splattered everywhere, not just Alicia's blood but Gabriel's as well. Fresh wounds that are bleeding profusely indicates that Alicia has just carried out the suicide attempt right after Gabriel's death. The tragedy of Gabriel's death puts a lot of pressure on Alicia and makes Alicia act impulsively.

\section{Conclusion}

Stress is a depressed condition experienced by an individual due to demands or inconsistencies and the reaction depends on how the individual copes with it. The chronic stress experienced by Alicia has characteristics, namely, impaired social relationships and nervousness. Impaired social relationship occurs when Alicia is reluctant to interact with her environment. Nervousness can be seen from Alicia's response to other people who try to interact with her, such as hesitation to act in front of others, wobbly walking, pale face, and shaking hands or feet. The type of stress that Alicia suffers from is chronic stress and the stress has an impact on her behavior.

As a result of stress affecting Alicia's behavior such as changes in the behavioral system to silence, aggressive behavior and self-injury. Alicia's silence has occurred since the death of her husband, Gabriel. This silence is Alicia's body's response to her mental unpreparedness for the incident. Alicia's aggressive behavior occurs when Alicia acts impulsively by brutally attacking other people. These actions include trying to slit Elif's throat during their confrontation in the canteen, and, strangling, slapping, and banging Theo Faber's head for trying to dig into his privacy. Self-injury occurs when Alicia tries to harm herself by attempting suicide. Alicia was seen slashing her hands many times after her husband's death.

\section{References}

Abrams, M. H, and Geoffrey, Galt Harpham. (1999). A Glossary of Literary Terms. Tenth Edition. Boston: Wadsworth Cengage Learning.

Chaplin, J. (2001). Kamus Lengkap Psikologi (terj.Dr Kartini Kartono). Jakarta: PT. Raja Grafindo Persada.

Fowler, Lastair A. (2001). A History of Literature. London: Basil Blackwell Ltd.

Jordan, M. JD. (1997). Specialized Training Manual on Psychosocial Counseling for Traffiched Youth. Kathmandu Nepal: ILO-IPEC.

Kartono, K. (2000). Hygiene Mental. Jakarta: CV. Mandar Maju.

Klonsky, E. D. (2011). Nonsucidal Self-Injury. Canada: Hogrefe.

Krahe, B. (2005). Perilaku Agresif. Yogyakarta: Pustaka Pelajar.

Mazelis, Ruta. (2008). Self-Injury: Understanding and Responding to People Who Live with Self-Inflicted Violence. Article of Mental Health. National Center For Trauma-Informed Care (NCTIC). Vol 2, No 25.

Michaelidas, Alex. (2019). The Silent Patient. New York: Celadon Books.

Palupi, Widyastuti. (2004). Manajemen Stres. Jakarta. Egc

Priyoto. (2014). Konsep Managemen Stress. Yogyakarta: Nuha Medika.

Sarafino, Edward P., et.al. (2015). Health Psychology: Biopsychology Interaction. Researchgate.

https://www.researchgate.net/publication/270899066_Health_Psychology_Biops ychosocial_Interactions 
Stress In Alex Michaelidas' Novel The Silent Patient, Mai Sarah, Asnani

Spielberger, Charles. (1979). Understanding Stress and Anxiety. London: Harper and Row.

Walliman, Nicholas. (2010). Research Methods. The Basics. New York: Routledge. 